\title{
The Analysis on the Causes of Irrational Public Opinion in Network from the Perspectives of Individual Rationality and Public Rationality
}

\author{
Yang Lan \\ Sichuan Acdemy of Social Sciences, Sichuan Chengdu, 610071
}

Keywords: Irrational Public Opinion Individual Rationality Public Rationality

\begin{abstract}
In this burst period of social transformation and contradictions, the freshness and variability of social life often leads to the lags and failures of norms. At this point, the public opinions in the network era is highly performed as the public opinion in network, which has become a reflection of important and direct carrier of public demand for justice. It brings so tremendous impact to political, economic, social that it is particularly important to research, control and guide the public opinion in network. Although many scholars have paid attention to it, there are still some shortcomings in this study, such as overly underestimating the rationality of Netizens, and ascribing most of the irrational expression to the emotional expression. Given this, this paper attempts to interpret the causes of irrational public opinion from two new perspectives---individual rationality and public rationality, and to expound the relationship between the two and irrational public opinion.
\end{abstract}

\section{Literature Review}

Irrational Public Opinion in Network refers to the public opinion in network expressed by the Netizen in the form of irrational expressions. The irrational expression of Netizens refers to their utteranceexpression under the subconscious control of emotion, intuition and feeling, usually manifested as emotional anger or revealing privacy. A lot of Irrational Public Opinion in Network flooding the network, bringing great impactto the public vital interests and the government's credibility.

While the network widens the common people's voicing channels, the irrational behaviors such as abuse and human-flesh search also occur frequently. The internet media has almost no restriction on the irrational behaviors of netizens, which often makes irrational public opinion drowns out the sound of rationality and causes the extremalization of network events. In the longer run, the credibility of the network media will decline and netizens will gradually lose social responsibility. In recent years, the frequent emergence of the emotional and extreme expressions of Internet public opinion such as "Hype"'Spoof"'Network rumors"'"public opinion in network violence" and other anomie phenomena, makes people feel disturbing.

Individual rationality is a kind of limited rationality, so it often manifests itself as the subjectivity and personal interest of the subject, and lacks the publicity and the legitimacy. Public rationality is the benefit integration mechanism and ability based on civil society, spanning national rationality, Party rationality, interest group rationality and individual rationality. Therefore, the public rationality originates from and higher than individual rationality, which rids off the contingency and subjectivity of individual rationality, and owns objectivity and publicity. In the public opinion in network, using individual rationality and public rationality to analyze the Irrational Public Opinion in Network can under standthe social dynamics behind events and predict and judge the social psychology more accurate.

In the public domain, all kinds of rationality are freely expressed under the precondition of complying with the public rationality, that is, all kinds of rational need equal dialogue, communication and intercourse to express their interests and values, respect each other and find out 
the balance point and value consensus of both sides' interests. The social media public opinion is in the contradiction between rationality and irrationality, among them, the irrational factor is one of thecomplicated problems in leading and managing the public opinion in network. Therefore, promoting the public rational expression of social media is an important way to realize the fairness and harmony of society. Some scholars think that rational analysis of the causes of irrational network opinion is a concentrated reflection of social psychology, which can dissolve the social contradictions and make the public opinion expression channelunimpeded by changing the governance concept and the government function. Finally, it can help to realize the harmonious coexistence between social public and the public power, eliminate the social origin of irrationalnetwork speech, then the irrationalnetwork speech eventually will gradually tend to the rationality.

\section{Overseas research status}

In the field of irrational public opinion research, most of the foreign scholars just analyze specific single events. In the study of the role of public rationality and individual rationality in the public opinion in network, foreign scholars have studied the political election events, and the concrete theoretical construction is still in the exploratory stage. On the research method, the foreign research mainly takes the positivism as the traditional and leading method, which has formed comparatively mature research method. However, in China, scholars mainly deduce with logical reasoning, lacking of credibility. Chinese scholars still need to learn from the western research methods to standardize academic research.

\section{The background of Irrational Public Opinion in Network}

The emergence of public opinion can be said to be synchronized with the process of human development history, and now the so-called public opinion mostly refers to the "modern public opinion"under the background of the industrial revolution. Marx's viewsthe public opinion as "the actual refection obvious expression of and generalrelationship." ${ }^{1}$ After the Industrial Revolution, public opinion is characterized by strong spontaneity, common interests foundation, obvious characteristics of "bellwether",theinfluence of external factors, the necessary requirement of political freedom and more intenseresistance to repression, etc. In addition to the widely discussedspeech, there are behavioral manifestations. The public opinion magnitude is usually measured with the "Semantic difference scale", "Equal spacing scale" and so on. The formation of public sentiment or public opinion field effect usually need to meet people's communication frequency, adjacent density, openness and infection intensity or temptation degree in the living space.

The development of the internet has made the internet a "public domain", in which speech can be made, but it is questionable whether public opinion on the network has features such as "rational and discretionary debate" as Jurgen Habermas deems. At the same time, although the intensity of the network opinion can be traced to a certain extent, the range, quantity and group characteristics of the people expressing opinions are still difficult to be controlled under the current technology, so that some people question whether the public opinion in network can be called "public opinion"? However, it is undeniable that the network provides an indispensable platform for the exchange of opinions and the formation of public opinion.

When regarding the formation of network opinion as a collective behavior, it will be found that there are many similarities between the two: the individual often has great effect but is not fixed; the individual voice is easily drowned by the collective's; rational and logical results exist only in a few fixed situations, most of which are disordered and irrational. Due to the increasing volume of public opinion in network, the social influence caused by it has been unable to be avoided, especially the pat of irrational public opinion, which has a increasing influence on judicature and social institution. In addition, irrational public opinion, such as emotional public opinion, namely explicit public opinion, potential public opinion and negative public opinion, etc., have complex 
formationmechanisms, are easy to breed and spread and to cause underestimateddamage, even are difficult to control. The formation process can also be categorized as spontaneous public opinion, that is, the formation of public opinion without planning, organization, purpose and steps; and non-spontaneous public opinion, which is formed by the guidance of the outside world with plans and organizations.

Hegel once said: "Public opinion is the inorganic way in which people express their will and opinions, including all the occasional opinions, its ignorance and misinterpretation, and erroneous understanding and judgment." ${ }^{2}$ The Irrational Public Opinion in Network is one of the unavoidable results derived from the development of mass communication, is the product of the public opinion in network in social anomie. In terms of the development tendency in recent years, there are tendencies of exceed public opinion supervision, the prevalence of network nationalism, the critical realism and the pornography issues.

The emergence of irrational public opinion has a variety of factors to mutually restraint. The anonymity of the network leads to the "law does not punish numerous offenders ", including individual netizen psychology, the decrease of social and moral constraints, the imbalance of social structural adjustment, intensified social conflicts and the absence of gatekeepers. As a part of the collective, the individual is easy to lose individual rationality and falls into the group carnival. Even if there exists a small part of the rational individual, its voice is also extremely easy to be annihilated.

\section{Analysis on the generation mechanism of irrational public opinion in network}

The basic goal of individual rational behavior is to maximize individual interests under certain circumstances, which can be divided into three aspects: security, aseity and utility. Individual irrationality is to make some irrational and emotional serious expression or behavior in individual units. Public rationality is the rationality which takes the group as the unit to seek the maximization of its benefit. Public rationality is extremely difficult to achieve, unless the group pursue the common interests. For its performance on the Internet, when it comes to national or group glory, the voice of the public opinion will be more consistent, but once the resonance is beyond a certain degree, it is very easy to lead to public irrationality.

Individual rationality and public rationality are human's rationality, however, there are irreconcilable contradictions: individual rationality must be based on public rationality, while public rationality can be compatible with individual irrationality; public rationality must takes individual rationality as premise, but individual rational speech or behavior may not be able to guarantee the public rationality. In the generation mechanism of Irrational Public Opinion in Network, although there exists direct irrational public opinion in group, it often begins with the anomie of individual rationality. When the netizen is hidden behind the huge network user group and the "anonymity" network bringing, they will begin to test new identity. When this irrational emotion spreads to the group, the public irrationality arises, and the individuals in the group are no longer rational and conscious, but fanatical and dominated by the majority opinion of the group. However, this irrational emotion or consciousness is not an absolute quantity, there are many calm and rational voices, which will gradually be heard by the public in the waning period of public opinion.

Individual netizen can accept contradictions and discussions, but the group will not do so, so that it emerges two kinds of phenomena: rational individual voice and irrational reproach; or the rational individual does not have the right to speak, the two sides have incompatible opinions. Suppose that there is an absolute sense of individual rationality, but even so, there is doubt as to whether it can reach public rationality, because the absolute individual rationality is like a smooth sphere, without the most advantages. The excessive concentration of individual interests and voice, makes the voice of the group extremely slack.

The influence of the individual is limited, so the cause of the network irrational public opinion events with great influence is often public irrationality, manifesting as the group polarization. Some events or speeches, especially coming from the opinion leaders, can easily instigate the group sentiment, and cause group polarization events without control. In recent years, with the 
characteristics of wide range of information, fast reception speed and so on, new media such as Weibo have become the center of the outbreak of public opinion, and traditional media are located in control zone after public opinion transferring and official voice.

\section{Study on how to achieve public rationality}

In the network, once the individual is aware of the existence of the group, they will lack of sense of responsibility, their language and action are very easy to infect each other, for example, in October 2010, netizens' consistent verbal abuse and human flesh search in the case of Hebei car accident. When an event involves social justice, ideology and public power, it is easy to arouse the attention of netizens. At present, our society is in a period of drastic change and transformation, social contradictions are severe, then it will arouse the "irrational" expression caused by dissatisfaction and anger in the real society. The wrong voice of opinion leaders will also lead to the emergence of irrational public opinion, when irrational voices compose "the climate of opinion", public opinion in network must develop in irrational trend. New York Times wrongly reported in 2001 that "Iraq has weapons of mass destruction", which has been consistently recognized and disseminated by most media, gradually becoming dominant and leading opinion, fortunately it published a self-criticism article later for amendment.

In economics, Villefredo Pareto puts forward the theory of Pareto Optimality on individual benefit and collective interest, but reality is the comprehensive Pareto Optimality is impossible to realize, only partial. Public rationality can only achieve relatively and the absolute public rationality is impossible. In the formation process of the public opinion, the mainstream voice gradually expands and dominates the field of public opinion, so does irrational public opinion, so that if the spontaneous rationality is difficult to achieve, external forces are needed to restrain it. Correct and strong public opinion supervision and guidance, and perfect judicial system are the basic guarantee of promoting the relative public rationality of the netizens. The promotion of the media literacy of the network is also of great importance, so how to keep individual rationality include public interest is a long-term topic. The healthier individual netizen should be: avoiding random dissemination of irresponsible or unverified speech, functioning as a professional "public opinion leaders" timely on the irrational public opinions to make a positive response, possessing identification ability and self-control ability to the irrational information and behaviors.

\section{Conclusion}

The disputes between individual interests and collective interests is the most commonly mentioned in economics, and the balance of the Boxed Pig Game is the choice of solving the conflicts between individual rationality and collective rationality. That is, the big pig and the little pig need to cooperate for co-existence, to achieve the unity of individual rationality and public rationality. The public opinion in network can be rationally divided into rational public opinion and irrational public opinion, while the latter has greater impact on social, which is the focus of this study. In all kinds of public opinion, the emergence of irrational public opinion is by no means accidental, but has gone through a long process, in which the Irrational Public Opinion in Network has become one of the public opinion with most profound influence in recent years. It has so great influence on politics, economy and society that research, control and guide the public opinion in network is particularly important. In conclusion, the survival mechanism and the transfer path of Irrational Public Opinion in Network can not be separated from the irrational speeches or behaviors of individual and the group, and among them, how to achieve the relative public rationality is still worthy of our discussion.

\section{References}

[1] An Analysis of Irrational Public Opinion in Network[J]. Qiao Yijun. Media Research, 2015(3).

[2] Research on Irrational Public Opinion in Network [D]. Long Tan. University of Xiangtan, 2012. 
[3] A Probe into the Irrational Network Comment Phenomenon of Irrationality in We-media era Jia Xuqiang (Radio \& TV)Journal, 2016(4)

[4] Causes and Avoidance of Irrational Public Opinion in Network[J]. Lin Jinjin. www.qnjz.com. 2016

[5] Xu Xin. Rational Examination of Irrational Network Speech. Journalism Review, 2012(10)

[6] Feng Xiying. On the Irrational Problems of Current public opinion in network from the Perspective of Process. Social Science Front, 2011 (4)

[7] Wang Zili, Wu Fuguang. Public Rationality and China 's Social Mass Events. Henan Social Sciences, 2012(8) 